\title{
Cyborg Life: The In-Between of Humans and Machines
}

\author{
GLen A. MAZIS
}

\section{Where is the Between of Human and Machine in Cyborg Life?}

Just as we can explore how humans and animals are "between" each other, as both being embodied in ways whereby they gain their sense of themselves through the surround and also as overlapping in their being comparably related to the surround ${ }^{1}$ - a topic being pursued by many phenomenologists currently_-so humans and machines increasingly criss-cross with each other in myriad instances within the surround. There are increasingly sophisticated developments in "embodied artificial intelligence" robots, for whom there is a continual feedback and response to aspects of the environment and to human actions. The "back and forth" with the surround creates a "between space" spanning robots and people or robots and aspects of the surround. However, for this paper I would like to consider what might be said to be a "doubly in-between" relatedness of humans and machines: human/machine cyborg beings. By looking at an extended example of a human implanted with computerized machinery, we will explore how their functioning together constitutes an "in-between space" of human and machine. Secondly, we will see how each evolves with the other in accomplishing new achievements for both, entering into an even deeper sense of the "in-between." In this second sense of "in-between," not only do human and machine share their functioning, but each becomes augmented in their capacities and possibly in their identities through the other. 
This second aspect of the "in-between" which focuses on the evolution in how machine and human come to work through one other allows us to see a temporal dimension of this cyborg being that is key to a larger point I would like to make in this paper: the "in-between," although we tend to think of it in spatial metaphors, is actually radically temporal. The "phenomenal stuff" of "between-ness" is the work of both the unifying duration of time and the folding back upon itself of time. It is through time that beings become so interwoven that they exist in some way through each other, in an "in-between" kind of being. In "folding back" on itself, we will see that time is not just a duration of what would be otherwise successive moments. It is also the coming together of moments that were "distant" from each other in time until this instant of "folding back" conjoined them. However, this temporal folding back on itself comes about only through the phenomenon of embodiment. The "between" in this second sense emerges through the temporality of a perceptual unfolding and a restructuring of the relationship between the body, the surround and past events that gives rise to a re-constellation of the temporal thickness and unfolding space which might be called an "interplace," to use Ed Casey's terminology (Casey 265). Analogously, this might more aptly be called an "intertime." These interplaces/intertimes are themselves apt to become folded into each other, as time folds back into itself. The bringing into relation of what otherwise might have been temporally disparate is an ongoing and continually further intermeshing process.

It happens that these two complementary but distinctive senses of the "in-between," stemming from the duration of time and time's chiasmatic nature, ${ }^{2}$ move us from a sense of the unity of "lived" time and space to the more radical enfolding of time within itself, a distinction that I believe corresponds to two senses of the cyborg which have been discussed by those interested in the human/machine in-between. The first and more traditional sense of "cyborg" is 
the case of organic beings who are physically and functionally united with mechanized beings to constitute what some consider "true" cyborgs. The second sense of "cyborg" claims that we have all become cyborgs in the sense of becoming enfolded within a world in which machines not only perform many of our key actions but also make possible how we know ourselves, express ourselves, modify our intentions, and open new avenues for who we might become. The issue of being a cyborg is not about implantation in bodies of machinery, for proximity of tools does not itself make them more than tools. Rather, what makes us become partly machine or cyborg is the way in which we are being put into question by machines, whether the machines have been implanted into our body or not, in such a way that we become transformed in who we are by our co-joint being. However, given the aim of this paper to return to a description of "the things themselves" by seeing this meaning emerging from a specific concrete example, I will keep these considerations brief. I will only provide a quick sketch of the issue of the temporally double "inbetween" and how it might make us all cyborgs, so that we might get to the phenomenological description of the case at hand, that of Michael Chorost's four year experience with a cochlear implant, detailed in his book Rebuilt: How Becoming Part Computer Made Me More Human.

In order to sketch out these two senses of the "in-between," I would like to turn to Merleau-Ponty's work for a moment, as the thinker who might well be called "the phenomenologist of the in-between," and point to how time is at the heart of his related notions of "reversibility" and the "intertwining" of the "flesh of the world." Reversibility is the sense within perception that as I am perceiving something; it is an inseparable part of my perception to have the apprehension of how I might be perceived by the object of my perception, as if it perceived me. This is a particular moment for Merleau-Ponty within the way I, as perceiver, am enfolded within the "flesh of the world." In separating himself from the ontology that Sartre 
articulates detailing the dualism of the cultural appropriation of the world, Merleau-Ponty uses as an emblem of reversibility how one's hands touching each other become simultaneously the touching and the touched, which is a sharp departure from Sartre's analysis of the discontinuous back and forth of each hand alternating as subject and then object of apprehension (Sartre 402). However, the overlapping articulated by Merleau-Ponty occurs within the duration of the unfolding of time. Taken as an isolated moment or a series of atomistic moments, the dualistic opposition stands. However, focusing on the ever increasing depth within time gives MerleauPonty another perspective in which he notes that despite the shifting back and forth of subject and object:

... this is not a failure. For if these experiences never exactly overlap, if they slip away at the very moment they are about to rejoin, if there is always a "shift," a "spread" between them, this does not prevent in time the metamorphosis of one experience into the other ... spanned by the total being of my body" (The Visible and the Invisible 148).

The sense that the hands are in some sense reversible, as are two speakers addressing each other, or the painter who confronts the tree he or she paints, occurs within a temporal process, and what might be distinct in an isolated moment in time, or in several such moments, comes to be blurred through the unity of lived time. We will see how this sense of inhabiting a lived space within the unfolding synthesis of time provides the in-between of machine and human to yield the first sense of cyborg.

In another equally famous passage from The Visible and the Invisible, Merleau-Ponty describes the sense of the flesh of the world found within a simple percept like a red dress by calling it a "straits gaping open" among an indeterminate set of beings and their relations. The red dress is:

a punctuation in the field of red things, which includes the tiles of roof tops, the flags of gatekeepers and of the Revolution, certain terrains near Aix or in Madagascar, it is also a 
punctuation in the field of red garments, which includes, along with the dresses of women, robes of professors, bishops and advocate generals, and also in the field of adornments and that of uniforms. And its red literally is not the same as it appears in this constellation or in the other, as the pure essence of the Revolution of 1917 precipitates in it or that of the eternal feminine, or that of the public prosecutor, or that of the gypsies dressed like hussars who reigned twenty-five years ago over an inn on the ChampsElysées. A certain red is also a fossil drawn up from imaginary worlds (132).

What has often been noted about this passage is how perception weaves together disparate aspects of the surround as well as differing modalities of apprehension such as memory, imagination, sensed qualities, proprioception, conception, et al., but what perhaps has not been focused on sufficiently is that the red dress example would indicate that each percept is also an interplay of temporalities: between now and the noted event of twenty-five years ago; among the hard red seen on roofs at a myriad of specific memorable times and just generally so; among the different times when the sight of differing reds may have been of the texture of the fuzzy, soft red of cloth that one's clergyman wore each Sunday, as well as the times she wore that sweater during that lovely summer or the holidays when one's aunt used that festive tablecloth; and the special weeks of vacation as a teenager when one saw the flakey red of the soil near Aix but also that six month period ten years ago when briefly living there; and the shiny red of silken borders of professorial robes when one was a student; of the red of all the tulips to come each spring or the fires that blaze in the dry areas in the decades to come as the water supply keeps dwindling; or the red of blood of casualties in Iraq echoing the blood of one's comrades fallen decades ago in Viet Nam; and also between perceived reds during one's life and the history of the world; and imaginal reds that have been brought to life at many other moments-the many different moments weaving together in the matrix of time.

This matrix of time of percepts is a rich "in-between" in which differing times do not just cohere in the self-unifying duration of time, but are the way within distinctive moments that 
startling discontinuities are enfolded within time folding back on itself. This folding back on and within itself of what were widely disparate moments is what Merleau-Ponty means when he comes to see "time as chiasm" as having a depth in which it "leaps" gaps in order to be one flow. He indicates this aspect of time when he notes that "a point of time can be transmitted to the others without 'continuity' without 'conservation'” (Visible 267). These flashings of time in which one moment comes to be joined with others "without continuity" suggests how moments of time become "piled up," enjambed, as "sudden reversibilities." The time of aspects of the "inbetween" may be more like a fractal constellation than that of a continuous "spanning" among moments. We may see that it is in this way, even though we may think we are not directly working with machines, that we might have become enfolded in distant mechanical processes that have restructured what our own histories have come to mean to us. We may have become cyborgs in becoming enfolded into a time where the history and future of the human has been reshaped by how machines bring new aspects of humanity into play. So, for example, when the machine determines that I have a genetic defect that will likely bring me and perhaps my children the same disease that my parents and grandparents had, their past becomes my past and an overwhelming present in a differing way, while also opening my future to a differing sense; my identity becomes fused with the time of the inauguration of the reading of genes and their significances brought about at a specific historical moment by varied machines. At the same time, a different reading by the machine indicating that I don't have this gene would make my parents' and grandparents' past not my own in another way, and would open an alternate future whose particular new possibilities for thriving would be inseparable from the machine's moment of intervention in my life. In this alternate scenario, my sense of my own time would fuse with its specific history wherein we were able to achieve this result and free humans from this worry. 
To see both the unfolding duration of time as opening the in-between of humans and machines in "cyborg life," as well as time folding back on itself to join what were disparate times in another sort of in-between, we can turn to and explore the richly detailed account of Michael Chorost's extended experience with his cochlear implant. Michael Chorost describes in detail his experience of being suddenly thrust into a new mode of existence that he could only understand as a wrenching transformation into being a cyborg. Chorost was thirty-six years old and a recent PhD graduate in educational computing, when suddenly he went from being able to hear fairly well with hearing aids, to becoming totally deaf. He was offered the chance to hear again by having a cochlear implant put in his skull. ${ }^{3}$ His experience can furnish us with a phenomenological description of what it is like to become transformed into a cyborg. We will see that Chorost's understanding of what this means shifts from an initial fear of having to live with a machine molding his sense of the world, to four years later seeing that his being as a person had shifted through the means of the machine into possibilities that were lying unrealized in his past.

At the beginning of his book, Chorost makes it clear that he is disconcerted by the loose way in which the term cyborg is being used. For example, he notes that "cultural theorists often claim in this day and age, everyone is a cyborg - that technological society has worked its will on all of us" (41). It is understandable, given his ordeal of having computer-driven machinery placed into his sensory system, that he does not want to dilute the forcefulness of the idea of being a cyborg to include everyone. In his definition, "[t]he essence of cyborgness is the presence of software that makes if-then-else decisions and acts on the body to carry them out" (40). Chorost's point is that some people's bodily functioning and experience will be dictated by a machine. He disputes that having silicon chips implanted in one's body in order to enhance its 
capabilities or to allow one to do what other humans normally do is to become a cyborg: “... cyborgs are physically fused with equipment" and have no choice but to live through the computer's programming, or else sacrifice vital functions.

However, by the end of the four years of living with his implant, Chorost is less adamant about the physical fusion of technology and flesh as being the definitive essence of cyborgs, nor does he feel that different from others. Rather than dictating his reality, the cochlear implant altered his reality in ways that called for him to change to meet these challenges, and these changes were not physical, but rather concerned his ways of being-in-the-world. Instead of feeling isolated from the norm, he realizes that most of us are cyborgs in the way technology has altered who we are and how we exist. Our ways of being-in-the-world have shifted and are shifting continuously in a dialogue with machines in our surround. He also sees a positive power in being a cyborg insofar as we are displaced from an objective world of set realities to a shifting one that gives us choices of ways to be. Cyborgs, for Chorost, and I agree with him, are beings who have become changed in who they are in some way which is not merely optional anymore. In other words, silicon chip implants that do not change one's relationship with the world or others, or that merely enhance an ability, do not make one a cyborg. To be a cyborg is to experience a transformation of one's sense of existence in such a way that one cannot be fully human or fully oneself outside of the link with certain machines. However, notice that this link does not require literal physical fusion. The key shift is on the level of the basic ways we form relationships with the world around us such that these relationships change who we are.

Initially, Chorost realizes that his hearing loss is not just a sensory deficit, but is more deeply about the body's power to "be-in-a-world," to be enmeshed with the things about one: “... the sense of hearing immerses you in the world as no other ... Hearing constitutes your sense 
of being of the world, in the thick of it. To see is to observe, but to hear is to be enveloped" (9). Hearing, perhaps even more acutely, and yet also like the rest of perception, is not about registering the world distantly, but "plunging into it"-being incorporated into it. Chorost realized that in some very real sense the world would be different for him: "The world mediated by the computer in my skull would sound synthetic, the product of approximations, interpolations, compromises" (9). There is a sense in which we are machines, biological machines, and the world is a result of that operation we consider "normal" —of how sound waves are translated into phenomena that are heard by us as a result of the workings of our common biological machinery. It is because of this kinship of the body with what we consider to be purely "mechanical" machines (which we misguidedly regard as utterly foreign) that the "in-between" of body and machine unfolds. However, the sense of kinship between body and machine would not be seen by Chorost until he had gone through a long process of discovery. At this initial point, the foreignness of the machine meant to him that as a cyborg his world would be altered by a foreign power. This was Chorost's fear before the implantation, and it is also his experience afterwards. Sometimes, the feeling was more acute than at other times: "I could hear clocks ticking across a room, but I did not feel like a hearing person. Hah! I was the receptor of a flood of data" (73). Embodiment allows us to be what we are hearing, and not take it in at a distance as data. So, at first, the implant/machine disrupted Chorost's embodiment. However, embodiment is a process, a matter of time and evolving relationships with the world. Chorost knew this before the implantation when projecting this cyborg body: "My body would have bewildering new properties and new rules, and it would take me weeks, months, even years, to understand them fully" (9). His chronicle is testimony to how embodiment changes in relationship to the world around it. Like the two hands coming to blur in their boundaries, a cyborg being depends upon 
this temporal unfolding within the ongoing unification of time to create the "in-betweenness" of human and machine.

This power to shift us away from a past norm seems at first to be a destructive aspect of the machine that tears us away from the "natural" human and animal life. Both the world has been altered through computer mediation and the body has been altered by having a different sense of the world, and it may seem like "damage." For anyone in this position, the overwhelming sense may be that they are prevented from "going back" to some previous sense of hearing taken to be the norm. Now, their only choice is to keep moving on to a new sense of hearing-one that emerges from a new world and a new body. In some way, Chorost found himself with a new kind of hearing, one that was hard to translate into what he had experienced before with his hearing aids. He had to give up on the sense that there was one way to be in the world, one way to experience the world, for his hearing through the implant would be different: "It would not be hearing. It would be the equivalent of hearing to hearing" (79). As he realizes this, Chorost says "goodbye" to reality, for he assumes, as most of us have been taught, that there is one reality to which we all aspire with objectivity to reveal and impact.

From this perspective, he could only assent to the idea that "I learned that my hearing had not been restored. It has been replaced with an entirely new system that had entirely new rules" (81). What Chorost gradually realizes, however, is that what at first seemed to him to be a purely "artificial" creation of the machine's power to change the flow of his existence was just another deviation from some sort of expected flow that had merged as the norm of the interweaving of the natural and cultural worlds. In some sense we are always deviating from past givens in the power of transformation that opened for us the initial flow phenomenon that we felt was "natural." Whether this be found in the baby moving from a myriad of sounds and tones to be 
"talked into" language by parents and others and thereby coming to inhabit an entirely different auditory world, or in later openings of new sense such as learning about bird calls and suddenly hearing the birds' summons to one another, we always inhabit the sensory worlds of embodiment by "re-inhabiting" them continually. This is at the heart of Merleau-Ponty's declaration that each moment of perception "is a birth and is a death" (Phenomenology 216). The machine intervention here may help us to see how our embodiment and our sense of meaning is always a temporal transformation of what might otherwise be inert and continuous into an unfolding "inbetween" that is a matrix of new possibilities.

While bodies may have been seen as stable structures until this past century, it is now common sense to realize that the physical body is a process whose cells are continuously replacing themselves in ongoing intervals. The physical body is a flow phenomenon. It is now widely known that even the brain is capable of remapping itself by weighting inputs differently through its networks of neural connections; we know that it can reorganize its structure over the longer term by growing new connections between neurons, in what is termed the brain's socalled "neural plasticity." This was a discovery that soon came home to Chorost: "Thanks to neural plasticity, the neurons in my auditory cortex were slowly reorganizing themselves to handle the bewildering new input from the implant" (88). Disturbing sounds and aberrations changed in their significance or disappeared because, as Chorost relates, "over the weeks and months my auditory cortex obediently refined its topography, making physical distinctions where none had existed before. The implant was literally reprogramming me." The phenomenon of Chorost's hearing is an "in-between" of human and machine, and the sense of each was transforming, too. This is the first or traditional sense of cyborg, the modification that takes place 
in the interaction between embodiment and machine as an ongoing improvisatory duration where the contribution of each is "worked over" by the other.

For this essay, it is important to note that when the computer, the machine, is intimately joined with the human body, it is in dialogue with the physical makeup of that body and its neural network. The neural network's plasticity adapts to what is around it through feedback loops that incorporate new pathways. Insofar as our own body has a mechanical dimension, it is one that adapts, that comes to meet the world around it or inside it to attempt to find a way to thrive and to make sense of experience. If the autonomic, the organic and the visceral comprise that biological dimension of our existence that is seen as its mechanical dimension, then the mechanical has been miscast as the purely invariant, the unresponsive, and the unrelated. Even the more mechanistic parts of ourselves, like our neural functioning, are temporal phenomena that are open to relational dynamisms; their unfolding in time changes what they are and what future unfoldings are possible, such that new aspects of the surround become integrated into them, and their being is between themselves and other beings through their relation within the surround. In the traditional sense of cyborg, there is a way in which we have always been part machine, biologically, but only if we also come to rework our idea of machine from simple invariant levers and pulleys to feedback structurings in a dynamic field of constant transformation of all parts by all the parts to which they are related. Cyborg being does not indicate that part of human being is rigidified and inert, but rather that there are additional articulations of our capacities that are dynamically related to both the materially shifting surround and its varying senses altered by our evolving existential being-in-the-world. ${ }^{4}$ 


\section{The Existential Between of Humans and Machines as Cyborgs}

However, beyond the physical adaptation of the body to the direct input from the machine are more existential shifts that are required of Michael Chorost in order for the implant to facilitate full functioning in the world. Through his experience, we see that the existential and the physical are not separable; both are aspects of embodiment. Chorost is startled when one day he realizes that his way of being concerned about other humans must change in order for the machine to be able to function as mediation with the world. Merleau-Ponty documents how perception works to give us a maximal sense of the world only when the person perceiving is invigorated by the "perceptual faith" of our sensory being. This "faith" is comprised by our openness to the richness of our experience and our plunging into its vitality in order to hearken to what calls us from all corners of the world to be experienced by us. Perception begins with the immediate sense that there is further meaning to be discovered by allowing the flow of the unfolding of one's perceptions to capture one's attentiveness. Attention is the response to a beckoning, but this beckoning can only have efficacy if one has the faith that there is more here to be discovered. This faith is an implicit commitment to work through what can come to be understood through the unfolding perception. When we "pay attention," we are not throwing an inert, indifferent "searchlight" onto the scene about us. We are actively looking at something that promises to mean something for us. If we are more attentive, more expectant, and more engaged in finding whatever as yet muddled sense it has first presented to us, it will yield more meaning (Merleau-Ponty, Phenomenology 214). This attentiveness develops into a "positive" feedback loop. In some way, whatever we perceive "beckons" to us and is an invitation to enter a dialogue with the promise of further meaning. However, it can only become such an invitation if we 
sensitively meet it and enter into the depth of its sense, and thereby allow a true encounter to occur.

At one point in Chorost's attempt to adjust to his cochlear implant, overwhelmed by frustration, he avoided speaking on the phone, especially with his mother, because he could not bear to want to hear and to not be able to hear. As he started to have positive experiences with his new implant, Chorost made the call to his mother with a new attitude—believing there was something for him to hear. To his amazement, he realized that he understood her, that he heard her. He was struck at that moment by an insight:

And yet I was understanding her. Believing that I could do it seemed to be half the battle. That let me extend myself into the sound and let it sink into me. If I didn't believe I could do it, I became a wall rather than a sponge: the sound bounced off me without penetrating. It was like the difference between looking blankly at an object and seeing the object (99100).

On an immediate level, Chorost had started to change his relationship to the auditory world. He was leaning into it now with the expectation beginning to dawn that it would open for him in a meaningful way. He started to believe in its sense for him, as an effulgence of significance that could be garnered.

Once we are oriented, both on the level of our immediate hearkening in an emotional attunement to the perception of things and consciously turned towards them, then we are able to swim into the sense of their presence. Allowed to plunge into the depths of perception, to be engaged and attentive, to become attuned, the world sings to us in a different way or shines or touches us. Here, we see how a practical space within his surround, the space of telephone conversations with those he cares about, opened up for Chorost as an in-between space between his own ability to hearken and the cochlear implant's facility at translating and transmitting to him the sounds of their voices. Now the past frustration and isolation are transformed in this 
temporal unfolding, bringing together his new faith and attentiveness with these upcoming opportunities in order to cast new future horizons for him. However, we see in following Chorost's description that two more dimensions to this openness are needed in order to allow the interweaving of embodiment, machine, and world that will allow his perceptual possibilities to be achieved.

Actually, although I have framed it this way for clarity of presentation, believing in his ability to work with his hearing to add sense to his life was not Chorost's first breakthrough. I have presented it this way, because the belief in the richness of what is perceivable is perhaps the initial prerequisite to opening up the deeper significance of the perceptual world. But there is also a particular kind of spontaneity required of perception for its full sense to emerge. A level of experience can occur spontaneously in the midst of our alienated struggles in some situations. Earlier, in the months after the implant had been installed, Chorost struggled to make sense of the garbled sound he was experiencing. Yet, one day, on the way to work, he was taken off guard by a sudden ability to hear and make sense of his car radio. At first, trying to hear what was being broadcast, Chorost was frustrated by hearing only "pseudo-English," something that sounded like English, but only came to him as very reasonable sounding nonsense. However, as his attention drifted off to concentrating on driving and thinking about the Halloween costume that he was going to get, he realized that parts of the radio broadcast were being heard and understood by him perfectly. When he was surprised to realize this and tried to listen to the radio again, it again sounded like nonsense. He was puzzled, but realized that he hadn't really been paying attention to the radio-and that's when he suddenly heard it. He allowed his attention to wander back to being absorbed in the road and driving, and to thinking about his costume. Sure enough, the radio started to resolve into understandable bits again! 
So, as Chorost thinks about it, the answer is one that does not fit the dominant Western "yes" or "no," one or zero, binary logic. The key to really hearing was that Chorost "had to pay attention. Just not too much attention" (90). He tested this out further and found that indeed the radio drifted in and out of focus as he "played with different levels of attention" (90). He thought of it using the apt analogy of finding "the sweet spot" on a tennis racket, which like listening requires some sort of attunement, being in a flow with things around one, but not willing, not trying forcefully, just being alert in an unfocused way. As Chorost says, it's hard not to try to explicitly focus, and then refrain from forcing it once it starts resolving, but to force it only destroys the attunement and perception. Chorost concludes, "You have to be calm, open, relaxed alert. Poised at exactly the right mental place between idleness and tension" (91). This description fits the lived sense of the sort of embodied understanding that is attuned to its surround, that is enmeshed in it, but on a prereflective level. Merleau-Ponty describes how as the body attunes itself to the environment as a whole, it takes in the sense of the surround in a way in which items form a constellation or a gestalt, an overall organization, which draws upon our felt and habitual relationships. There is no need for a deliberative, reflectively directed focus for this sort of "lived" or "embodied" understanding. Actually, it dissipates as we turn our reflective focus upon it or will ourselves to the same sort of relationship.

In addition to being attuned to what is around one beckoning to be perceived, and being drawn towards deepening its sense, there is another dimension to this kind of openness. The upsurge of the sense of the world in perception has to be allowed by a kind of "giving oneself over to the world" or what Heidegger might call a "letting be" [Gelassenheit]. The world often reveals its sense if it is hearkened to by allowing it to flow out to meet us rather than wrestling it into our grasp. We have to let our attention be captured, not willed. We have to be open to the 
world as a partner in dialogue that has to be given the space to form. This "interspace" or between space forms as allowing a flow to form, as opening to a possible dialogue, as a process which needs time to unfold and invite us into its temporal expanse or emerging "intertime." Merleau-Ponty makes the analogy between attuned perception and sleep, where we have to let it happen, to "come over us," for if we try to will sleep, it will not happen (Phenomenology 163). Similarly, with the fullness of perception and its relational understanding with the qualities of things, one has to let go into the perception. This letting go is an art that can be learned.

This "letting be" of the surround is not only a matter of modifying the will or ego or of immersing ourselves in a certain kind of attention, but in addition, it concerns the emotional relationship to what we might understand is vital. The space within which we are interwoven is not just a set of factual occurrences or indifferent objects. This space is criss-crossed with vectors of sense about which we have feelings. Part of our connection to this space through embodiment is affective. For example, someone may be anxious about being in a part of town because there has been a series of crimes in this locale lately, or is fond of this neighbor and therefore is apt to pay more attention to him than to someone else who lives next door on the other side, or feels comforted in this chair at the end of the day since it offers rest and has associations of many books read in its confines, or feels afraid of the set of eyes glowing in the forest on this person's nightly walk, and these feelings change the person's access to these things. Feelings alter the orientation towards phenomena and the felt connection with them makes us able to know them in different ways. So, in the examples just described, one might suddenly see shortcuts in the streets in the threatening neighborhood or notice ways one might be able to help the neighbor one cares about or notice that the beloved chair needs some minor repair. One apprehends what one might otherwise miss, if it weren't for the emotional pulls that one experiences. Merleau-Ponty gives a 
striking example of being in the south of France during the war and being utterly immersed in the village life, until he hears that Paris has been bombed. Then his worry orients him utterly to Paris, and he feels disconnected from where he literally is located. The small details of village rhythms and surroundings that had fascinated him become inapprehensible as he is riveted to Paris by his worry (Phenomenology 285). Fear makes some objects heightened and makes us closed off to others, just as love makes us able to perceive some aspects of another person that had been hidden, but perhaps not able to see others. In indifference, however, much of our perceptual, affective lived understanding glides by in the background unexperienced by us.

Things are not all felt to the same degree, so they do not register with us to the same degree, and are not the focus of our directedness, connectedness and ability to explore them to the same degree (Mazis, Emotion 69-89). Emotional orientation to something or someone is the "glue" between the person and the surround as one becomes immersed through feeling in an affective space. Therefore, it is not surprising to see in the case of cyborgs that emotional openness is part of the indirect way that machines are joined with humans to gain access to parts of the surround. Chorost comes to realize this during the four years of adjusting to his implant. It is a discovery that he had made earlier with his hearing aids. During a group therapy meeting in the late 1990's, the radio transmitter that had previously broadcast to Chorost's hearing aid in order to help him hear the members of the group went dead. To his surprise, unlike other times when his batteries did not function, he could still hear people on the other side of the room. He realized that through the therapeutic process, he had overcome his emotional isolation and had begun to feel an emotional kinship with these people and their problems. As a result, as Chorost puts it, "What had changed, I suddenly realized, was my ability to listen. Not to hear, but to listen" (78). As he meditated on this, he realized that if he could become a more caring person, 
concerned about what others were saying and able to feel his connectedness to them, he could hear them better. In his dialogue with the cochlear implant, Chorost is being urged to go further in his transformation to a more emotionally open and caring person.

He recalls this lesson from his past as he is struggling with his implant and realizes that in order to become able to hear with the potential that the machine has provided him, "I would have to become emotionally open to what I heard" (78). The machine certainly helps to create his context, both internally and inescapably, as allowing him to be woven into what is going on around him in an auditory way. Yet for the machine to work, it needs him to develop a closer relational bond to people and events around him. He must weave an existential context into which the machine can insert itself. If this example holds, then for humans to experience the way machines can open parts of our world and become more akin to us will require an emotional relatedness to things of which they can be a part. We think of machines as functioning through indifference, but insofar as a partnership forms, a possible overlap of human and machine, it requires a care from the person towards that in the world which is to be better revealed and understood. For the machine's function to be realized, it may call upon us to realize more of our potential as social beings.

This "in-between space" is a richer one that requires all those moments, even if they are widely distributed, somehow to come to reverberate together, like the widely scattered moments of differing reds, to give a cogent sense of care and openness, into which the machine can be creatively interwoven to augment our initial human capacities in cyborg being. Our potential does not lie like a neat path behind us. It is scattered in moments of discovery and openness, and then lost again at other moments and stretches of time to other ways of being, and within other less congenial contexts of our lives. Chorost is able to pull together repressed and scattered 
dimensions and moments of his being to become a more caring, open and responsive person who then can utilize the cochlear implant in a more powerful way to communicate with others, a way that allows the machine also to gain a greater level of efficacy. This level of temporal bringing together of our disparate parts and allowing machines to augment our humanity takes a deeper entry into time than merely letting its syntheses occur through learning how to attune oneself to the co-joint working of human/machine. It is this aspect of intermeshment that I have called the second sense of "in-between" throughout this essay. It is rather more like the moment when Melville's character, Ishmael, exhorts himself to "take a deep dive" into the depths of the world and psyche that had been lost and scattered to him in the "drizzly November of his soul" (Melville 23, 26), but which can be recovered. So, for Chorost, these moments of increasing engagement become folded back into earlier breakthroughs, reinforcing them all. As he became more open with women that he was dating, for example, or with friends, these moments opened up in an immediate or "lived" way to the earlier moments of dawning openness, like those with his therapy group years before. The between in this sense emerges from among varied times that twist about each other and combine in their sense becoming a new "fuller" present and yet notas the past times still retain a sense of their old disparateness that has suddenly become reconfigured. These moments were not successive but at odd junctions in one's history, but suddenly through the flesh opening to new sense they become conjoined in a new depth of the moment in which the temporal distinctions are overcome. In this way, we see how time folds back and intertwines with earlier moments that come to be "side by side" or joined through juxtaposition like places on interlacing helixes of DNA. The in-between of human and machine opens as these disparate times open to each other; there is a transformation in who the person is or has become and the machine now functions in a different existential context. 
This is the more hopeful and constructive side of this interplace/intertime between human and machine. In this paper, I have not discussed how there can also be a betweenness that opens where disparate desires to dominate coalesce with the greater possibilities for power and violation offered by the machine. A desire to control citizens that has a long past can unleash a terrible space of fear between humans and between humans and their governments with the addition of electronic and computer-driven surveillance methods. Perhaps, a person's past already riddled with periods of abuse and pain leaving them more indifferent to others can mesh with the cold, grinding gears of the machine to augment a life of indifference to other beings as a destructive in-between of cyborg existence. This, of course, is probably the more common fate of our dawning cyborg life, woven into a technological world where we only know ourselves as identified by the power we harness, driven by a hurried pace of machine-facilitated mass production, seeing everything as possibly reengineered to serve our productive will and drive for consumption, where the appeal to the caring, responsive human is made difficult within clanging rhythms of destructive inter-being. Yet, there are cyborg possibilities that could not only augment our practical capacities, but in doing so, may summon us to deepened humanity. Like Chorost, we could use the computer and the machines within and without us to become more creatively ourselves.

\section{Notes}

${ }^{1}$ For example, the Clark's nutcracker is a bird that stores thousands of pine seeds in approximately two thousand caches in its surround before winter and can remember where these seeds are stored with amazing accuracy. It remembers in an immediate bodily sense since the features of its habitat are read perceptually as distinctive places arrayed around it, having a distinct place by being woven into the fabric of its project of surviving the harsh winter. The caches are almost extensions of its own body. Similarly, human beings live in an environment with myriad places arrayed around them that have a felt, bodily significance in the trajectory of being able to proceed with their projects. Their similar relationship to the surround opens up a 
"between" of humans and these birds in how they inhabit their world together. For a discussion of this and other examples, see Mazis, Humans 24-28.

2 'The Stiftung of a point of time can be transmitted to the others without 'continuity,' without 'conservation,' without fictitious 'support' in the psyche the moment that one understands time as chiasm" (Merleau-Ponty, Visible and the Invisible, 267).

${ }^{3}$ In people with normal hearing, the conducted sound from the eardrum and the three tiny bones of the inner ear is further transmitted through the fluid of the cochlea which in turn perturbs the 15,000 cell-sized hairs located in the cochlea. Each of these hairs connects to a nerve ending that sends sound messages to the brain. The implant simulates the action of the hairs with a limited number of nerve endings by using electrodes to stimulate the neurons. A microphone picks up sound waves, attached to the implant by a magnet, makes them into an electrical current sent down to a computer processor down at the waist, which turns them into bits of data, and then sends them by a wire through the skin to computer chips in the implant and fires electrodes (in Chorost's case only sixteen) to stimulate the neurons. In Chorost's chronicle of his first four years with this computer implant in his skull, his thinking about the relationship of humans, animals and machines undergoes profound changes.

${ }^{4}$ For thinking about machines in this way, see especially chapter three in Mazis, Humans, Animals, Machines (2008).

\section{Works Cited}

Casey, Edward S. The World at a Glance. Bloomington: Indiana University Press, 2007.

Chorost, Michael. Rebuilt: How Becoming Part Computer Made Me More Human. Boston: Houghton Mifflin, 2005.

Mazis, Glen. Emotion and Embodiment. New York: Peter Lang, 1994.

-. Humans, Animals, Machines: Blurring Boundaries. Albany: State University of New York Press, 2008.

Melville, Herman. Moby Dick. Indianapolis: Bobbs Merrill Co., 1964.

Merleau-Ponty, Maurice. Phenomenology of Perception. Trans. Colin Smith. New York: The Humanities Press, 1962.

—. The Visible and the Invisible. Trans. Alphonso Lingis. Evanston: Northwestern University Press, 1968. 
Sartre, Jean-Paul. Being and Nothingness: An Essay in Phenomenological Ontology. Trans. Hazel Barnes. New York, Washington Square Press, 1993. 